\section{MANIFESTAÇÕES TORCEDORAS E TERRITÓRIO: CONFIGURAÇÕES DAS IMEDIAÇÕES DA ARENA DO GRÊMIO}

\author{
FOOTBALL FANS' DEMONSTRATIONS AND TERRITORY: \\ ARRANGEMENTS IN THE SURROUNDINGS GRÊMIO'S STADIUM
}

\author{
MANIFESTACIONES DE LOS HINCHAS Y TERRITORIO: \\ CONFIGURACIONES DE LAS INMEDIACIONES DEL ESTADIO DEL \\ CLUB "GREMIO"
}

\author{
Daiane Grillo Martins*, Alan Goularte Knuth**
}

Keywords:

Sociocultural Territory.

Soccer.

Sports and

Recreational

Facilities.

Palabras clave: Territorio sociocultural. Fútbol. Instalaciones Deportivas y Recreativas.
Resumo: Os tempos e espaços referentes às manifestações torcedoras não se restringem ao interior dos estádios de futebol. Assim, buscamos compreender como se configuram as relações de apropriação do espaço das imediações da Arena do Grêmio no período que antecede os jogos no estádio. Realizamos uma pesquisa etnográfica em sete jogos do Grêmio Foot-Ball Porto Alegrense em 2018, com observações, anotações, caminhadas, conversas, fotos, vídeos e diários de campo. Observamos que o público diverso formado por torcedores, comerciantes, policiais, vendedores ambulantes, catadores, entre outros sujeitos, constitui microterritórios em rede, formando a totalidade territorial. O território é mutável nas combinações de clima, tipo e fase da competição, adversário, mas também é estável, nos fatores sociabilidade e relações comerciais. Concluímos que as imediações da Arena do Grêmio é território de ambiguidades, configurado na multiplicidade de inter-relações, significados e pertencimentos.

Abstract: Times and spaces of football fans' demonstrations are not restricted to stadiums. Therefore, we seek to understand how relations are established when the space surrounding Grêmio Foot-Ball Porto Alegrense's Stadium is appropriated before matches. We conducted an ethnographic study on seven matches in 2018 , with observations, notes, walks, conversations, photos, videos, and field diaries. We observed that the diverse public of fans, small business owners, police officers, street vendors, waste pickers, among other subjects establish a network of micro-territories that form the territorial totality. The territory shifts as a result of combinations of weather, competition type and stage, and opponent. But it is also stable regarding sociability and commercial relations. We concluded that the stadium's surroundings are a territory of ambiguities, arranged in its multiple interrelations, meanings, and belongings.

Resumen: Los tiempos y los espacios referentes a las manifestaciones de los hinchas no se limitan al interior de los estadios de fútbol. Así, trataremos de comprender cómo se configuran las relaciones de apropiación del espacio en las inmediaciones del estadio del Gremio en el periodo que antecede a los partidos. Realizamos una investigación etnográfica en siete partidos del Gremio Foot-Ball Porto Alegrense en 2018, con observaciones, notas, caminatas, charlas, fotos, videos y diarios de campo. Observamos que el público diverso, formado por hinchas, comerciantes, policías, vendedores ambulantes, recolectores de envases, entre otros, constituye microterritorios en red, formando una totalidad territorial. El territorio es mutable según combinaciones de clima, tipo y fase del torneo y del adversario, pero también es estable en lo relativo a factores de sociabilidad y relaciones comerciales. Concluimos que el entorno del estadio es un territorio de ambigüedades, configurando una multiplicidad de interrelaciones, significados y pertenencias.
*Universidade Federal de Pelotas, Pelotas, RS, Brasil.

E-mail:

daia.martins82@gmail.com

**Universidade Federal do Rio Grande, Rio Grande, RS, Brasil. E-mail:

alan_knuth@yahoo.com.br

Recebido em: 16-12-2019 Aprovado em: 11-05-2020 Publicado em: 12-06-2020 (c) (i) (8) Licence 


\section{INTRODUÇÃO}

Quando nos remetemos aos Esportes dos tempos atuais e, mais especificamente, ao futebol profissional, é possível constatar que esta prática agrega diversificados atores envolvidos na sua difusão social e na manutenção dos clubes. Dentre esses sujeitos, destacamos os públicos torcedores, os quais, segundo Damo (2002), se caracterizam pelo sentimento de pertencimento clubístico, atribuindo às suas identidades, símbolos, linguagens e significados específicos.

No contexto clubístico, os estádios de futebol, geralmente, assumem a função de sede do clube e são eles, essencialmente, o palco do espetáculo. Entretanto, é importante destacar que o mesmo que ápice do universo futebolístico seja o momento do jogo, isso não significa que torcedores/as frequentem estádios de futebol, pois o torcer se estabelece a partir do engajamento emocional, das relações afetivas de cada sujeito com determinado clube (DAMO, 2007). Portanto, existem várias formas de manifestar o torcer que ultrapassam as dimensões espaciais-temporais dos estádios, como, por exemplo, os espaços-tempo inerentes às interações proporcionadas pelas transmissões televisionadas, internet e redes sociais.

Visando analisar o "espaço-tempo vivido"1 das manifestações relativas aos torcedores e torcedoras frequentadores/as de estádios de futebol, é necessário destacar que estas relações não ocorrem somente dentro destes espaços. Também podem acontecer em outros territórios, como no lado de fora dos estádios, nas suas imediações, nos tempos pré, durante e pós-jogo. Partindo dessa prerrogativa, realizamos uma pesquisa de campo no bairro Humaitá ${ }^{2}$, na cidade de Porto Alegre/ RS, onde tivemos o objetivo de compreender como se configuram as relações de apropriação do espaço das imediações da Arena do Grêmio, provenientes das manifestações torcedoras, no período que antecede o horário dos jogos no estádio.

\section{TRAJETOS TEÓRICO-METODOLÓGICOS}

Para a realização desta investigação ${ }^{3}$, nos embasamos na etnografia, entendida como "a arte e a ciência de descrever um grupo humano - suas instituições, seus comportamentos interpessoais, suas produções materiais e suas crenças" (ANGROSINO, 2009, p. 30). Na pesquisa etnográfica, constituem-se processos indispensáveis que Oliveira (2006) denomina por "etapas de apreensão

1 "Enquanto 'espaço-tempo vivido', o território é sempre múltiplo, diverso e complexo [...] Podemos então afirmar que o território, imerso em relações de dominação e/ou de apropriação sociedade-espaço, desdobra-se ao longo de um continuum que vai da dominação político-econômica mais 'concreta' e 'funcional' à apropriação mais subjetiva e/ ou 'cultural-simbólica'”. (HAESBAERT, 2007, p.21).

2 O Humaitá localiza-se na zona norte de Porto Alegre, a $8 \mathrm{~km}$ do centro da cidade, limita-se, ao sul, como o bairro de Navegantes e, ao norte, com o município de Canoas. Na década de 1960, em uma área alagadiça que sofreu processo de aterramento, o Humaitá teve seus primeiros movimentos de ocupação. Entre os anos de 1996 e 2005, houve um grande crescimento populacional, devido à expansão das vilas e às invasões ocorrentes a muitos prédios construídos que não foram ocupados por seus proprietários. Já os anos de 2006 a 2009 são marcados pelo domínio imobiliário, denominando o Novo Humaitá, alavancado, pelo promissor complexo de entretenimento que contemplava a construção da Arena do Grêmio (MARTINS, 2010; BIANCHI, 2012). Situada ao norte do bairro, a Arena, passou a ser a nova casa do Grêmio Foot-Ball Porto Alegrense, substituindo o Estádio Olímpico Monumental. Foi inaugurada em dezembro de 2012, caracterizando-se como um dos estádios mais modernos da América Latina.

3 Este trabalho é fruto de uma pesquisa que teve dois objetivos distintos. Além da apropriação do território, tratada neste artigo, também investigamos como as apropriações das imediações da Arena, nos dias de jogos, compõem a vida de sujeitos moradores do bairro Humaitá. 
dos fenômenos sociais" (p. 18). São elas: "o olhar, o ouvir e o escrever" (p. 18). Essas ações cognitivas, mesmo tratadas separadamente, são indissociáveis à interpretação dos sistemas simbólicos constituintes da rede de interações do grupo social que está sendo investigado.

Acrescentamos também as caminhadas no campo, pois para Silva (2009), na pesquisa etnográfica, andar, ver e escrever são três fluxos dinamicamente interrelacionados, que exercem e sofrem influências recíprocas. Assim, realizamos observações, caminhadas, conversas e diários de campo. Também utilizamos imagens fotografadas e filmadas através de smartphone, de uso pessoal ${ }^{4}$, como instrumentos de auxílio para confecção dos diários de campo. Os trechos dos diários aparecem nas análises com algarismos romanos, em ordem cronológica, junto às datas referentes.

Considerando os aspectos éticos relativos à identificação dos sujeitos, foi assegurado anonimato, já que as conversas ocorreram de forma espontânea. Assim, os nomes dos investigados são fictícios. Com exceção de imagens que foram autorizadas verbalmente para divulgação, nas demais procuramos preservar o reconhecimento dos sujeitos, pois "a etnografia, como qualquer produção reflexiva, requer uma seleção do que pode e deve ser divulgado" (GOMES; MENEZES, 2008, p.3).

Iniciamos a etapa empírica mediante aprovação do projeto de pesquisa, no Comitê de Ética em Pesquisa (CEP), da Universidade Federal de Pelotas (UFPEL), que emitiu parecer de aprovação $n^{\circ} 2.897 .136$. O período de imersão no campo ocorreu no segundo semestre de 2018, de 23 de setembro a 02 de dezembro, totalizando sete idas a campo, em dias de jogos oficiais do Grêmio Foot-Ball Porto Alegrense, sendo cinco no Campeonato Brasileiro e dois na Copa Libertadores da América, contemplando todos os jogos do semestre esportivo em que a pesquisadora pôde estar presente.

A prioridade de espaço-tempo de imersão ficou reservada aos períodos que antecederam os jogos e à extensão da Avenida Padre Leopoldo Brentano, tendo início no Bar do Tricolor, até o Bar do Ito, na Avenida AJ Renner. Foi dada prioridade ao período pré-jogo, pois é quando há por mais tempo, a maior circulação de público no território.

Destacamos que as dimensões espaciais das imediações da Arena estão para além do território pertinente à pesquisa. Porém, foi preciso delimitar o espaço de investigação, para possibilitar uma imersão mais aprofundada. Então, além de um recorte temporal, também houve um recorte espacial, que se deu por meio da possibilidade de $v^{5}{ }^{5}$ o campo, considerando dois aspectos específicos: o cenário de permanência de maior número de torcedores/as, visualizando que no trajeto onde havia maior circulação de torcedores/as, as apropriações eram bastante fomentadas. Também por proporcionar maior sensação de segurança à pesquisadora, que circulava sozinha nesses espaços periféricos do estádio e da cidade.

\footnotetext{
4 A fase empírica da pesquisa foi realizada pela primeira autora deste trabalho.

5 "[...] ver, sendo diferente de olhar pura e simplesmente, implica uma organização do que foi olhado, espiado, espionado, entrevisto, reparado, notado, percebido ao longo do percurso etnográfico. Ver implica um olhar que se organiza; um olhar organizado e reorganizado; que vai organizando; que organiza e reorganiza; que vai revendo; que revê e dá por revisto" (SILVA, 2009, p. 181-182).
} 
Dependendo dos acontecimentos durante o processo de pesquisa, que vão desde o deslocamento até o campo e os fatos lá ocorrentes, o tempo estimado de permanência, a cada imersão, teve variações ${ }^{6}$. O menor período foi de aproximadamente uma hora e o maior foi de aproximadamente quatro horas. Em um dia de Libertadores, houve a necessidade de permanecer em campo durante o período do jogo, mesmo que a previsão projetada contemplasse, preferencialmente, o período pré-jogo. Essa situação se deu pela percepção pertinente à imersão, de que permanecer no território nesse período também poderia ser relevante para melhor compreender relações de apropriação. Isso porque, se tratando de pesquisa qualitativa, o/a cientista social tem como preocupação básica "a estreita aproximação dos dados, de fazê-lo falar de forma mais completa possível, abrindo-se à realidade social para melhor aprendê-la e compreendê-la" (MARTINS, 2004, p. 292).

\section{SOBRE A APROPRIAÇÃO DO TERRITÓRIO}

Conforme os trajetos teórico-metodológicos foram traçados, passamos a abordar o contexto das imediações da Arena, a partir da perspectiva de que Território “[...] não é simplesmente uma 'coisa' que se possui ou uma forma que se constrói, mas, sobretudo, uma relação social mediada e moldada na/pela materialidade do espaço" (HAESBAERT, 2010, p. 350). As relações com que nós, mesmo que no plano individual, funcionalizamos e significamos o espaço é mais relevante que as formas concretas que o construímos (RAFFESTIN, 1993).

Ao tratar da territorialização em tempos atuais, especificamente nos ambientes urbanos, Haesbaert (2010) considera a desterritorialização um mito e nos direciona ao entendimento de multiterritorialidade. Não seria o fim do território, mas a sua multiplicidade, que não é isolada, pois se estabelece em redes sobrepostas e descontínuas. Mais do que o fim dos territórios, não há indivíduo ou grupo social sem território, "[...] sem relação de dominação e/ou apropriação do espaço, seja ela de caráter predominantemente material ou simbólico" (HAESBAERT, 2010, p. 339).

Ao investigarmos a relação de apropriação do espaço, sinalizamos que as interações dos estratos funcionais ${ }^{7}$ do território devem ser analisadas entre si, pois para se

[...] entender estruturas e processos sociais, nunca é suficiente estudar um único estrato funcional no campo social. Para serem realmente entendidas, essas estruturas e processos exigem um estudo das relações entre os diferentes estratos funcionais que convivem juntos no campo social e que, com a mais rápida ou mais lenta mudança nas relações de poder provocada por uma estrutura específica desse campo, são no curso do tempo reproduzidas sucessivas vezes (ELIAS, 1994, p. 223).

\footnotetext{
6 O deslocamento da pesquisadora, por ser moradora do interior do estado, em quatro idas a campo, ocorreu através de excursão com grupo de torcedores/as gremistas, da cidade do Rio Grande/RS. Desse modo, as variações de permanência no campo dependiam do horário de chegada do ônibus às imediações da Arena, que de acordo com as condições da estrada e relevância da partida, chegava de duas a quatro horas antes do horário marcado para o início do jogo. Três idas ocorreram através de ônibus intermunicipal e aplicativo, pois já havia chegado à capital no dia anterior. Esse deslocamento antecipado ocorreu pra que nesses dias, a pesquisadora pudesse chegar mais cedo, visando observar as movimentações iniciais dos sujeitos no território.

7 Em diálogo com Norbert Elias, conceituamos estratos funcionais, os grupos de indivíduos que possuem características e funções semelhantes entre si, no que se refere às identidades pertinentes à configuração do território. Exemplo: torcedores/as, moradores/as, vendedores/as ambulantes.
} 
Desse modo, consideramos o território das imediações da Arena, em dias de jogos, como espaço de inter-relações de domínio e apropriação, pelos sujeitos que lá se encontram e compartilham espaço-tempo-vivido.

O território pesquisado possui aproximadamente 650 metros de distância entre as suas extremidades. A Avenida Padre Leopoldo Brentano é pavimentada, com duas vias para circulação de veículos e um canteiro central. Do lado da avenida, em que se localiza parte da Arena, não existem residências. Do lado oposto, encontram-se residências e estabelecimentos comerciais. Nas extremidades do campo, se posicionam fiscais de trânsito para controlar a movimentação dos dias de jogos. O policiamento circula pelo território, mas também possui seus pontos fixos estratégicos. Ao longo de todo território existem torcedores/as e moradores/ as. Cambistas exercem suas atividades, mas se fixam, prioritariamente, no entorno do estádio. Durante o período eleitoral estadual e federal, em que ocorreu parte da pesquisa, grupos de campanha de candidatos que possuem alguma ligação com o clube também estavam presentes.

Os pontos de comércio também se estendem por todo território, tanto que as extremidades são delimitadas por dois bares. São comerciantes locais e ambulantes ocupando as calçadas, o canteiro e a parte abaixo da rampa de acesso à parte superior da Arena e pelo entorno do estádio. Os/as guardadores/as de veículos ocupam lugares viáveis ao estacionamento, sejam eles públicos (ruas ou calçadas) ou privados (pátios ou garagens). Catadores/as também circulam permanentemente com seus sacos ou carrinhos coletores, em busca principalmente das latas deixadas pelos/as torcedores/as, após o consumo de bebidas. São homens e mulheres, jovens, adultos/as, idosos/as e algumas crianças.

Milton Santos aponta que "[...] é o uso do território, e não o território em si mesmo, que faz dele o objeto da análise social" (2005, p.137). Nessa perspectiva, apresentamos a análise dos usos do território pelos sujeitos do campo, classificandoos em dois grupos específicos: o público de deslocamento e o público permanente, que por sua vez, se divide em sujeitos estáveis e sujeitos circulantes.

\subsection{PÚBLICO DE DESLOCAMENTO}

Consideramos público de deslocamento os indivíduos que passam pelo território, mas não permanecem. Trata-se especificamente de torcedores/as que apenas se deslocam em direção ao interior do estádio. Eles/as chegam no horário entre a abertura dos portões e início da partida, em grupos ou sozinhos/as. Embora o público de deslocamento não seja a parcela torcedora que se fixa nas imediações do estádio no período pré-jogo, esses sujeitos também estavam presentes no território, mesmo de forma passageira.

Esse público estabelece inter-relação relevante com outros estratos, tais como cambistas e guardadores/as. Muitos/as chegam de veículo particular, que ficam estacionados nas proximidades dos estádios, locais onde diversos guardadores/ as exercem sua atividade econômica. Também se relacionam com ambulantes 
vendedores/as de artigos do clube ${ }^{8}$, principalmente na saída do estádio, período em que as vendas acontecem com maior intensidade.

Conforme o diário de campo $\mathrm{V}$, a ambulante Madalena conta que "[...] o faturamento é maior na saída dos/as torcedores/as do jogo, do que no período que o antecede, independente do resultado da partida". Fernando, outro ambulante, também relata que "[...] o período pós-jogo é quando as vendas são melhores e que permanece sempre no mesmo lugar: um ponto de ônibus que transforma em seu ponto comercial, na calçada onde se deslocam boa parte dos/as torcedores/as em direção à Arena" (11/11/2018).

Ambos ambulantes se fixam em posições estratégicas da Avenida Padre Brentano, visando o público de deslocamento, assim como diversos/as outros/ as localizados/as ao longo da avenida. Madalena e Fernando contam que o tempo de permanência no território depende da relevância do jogo. A ambulante relata já estar em seu posto "por volta de cinco horas antes do início do jogo, permanecendo em média de uma hora e meia, após o término da partida" (DIÁRIO DE CAMPO V, 11/11/2018).

Diferentemente do público de deslocamento, os/as vendedores/as ambulantes caracterizam-se enquanto permanentes, embora estabeleçam relações de interdependência com o público de deslocamento. Passamos agora a contextualizar o público permantente.

\subsection{PÚBLICO PERMANENTE}

Consideramos público permanente aqueles sujeitos que permanecem nas imediações da Arena antes, durante e/ou após o jogo. Além de torcedores/as, fazem parte os estratos de policiamento, fiscalização de trânsito, guardadores/as de veículos, comerciantes locais, catadores/as de latas, grupos eleitoreiros, cambistas e vendedores/as ambulantes.

Conforme Stuart Hall (2005), os indivíduos assumem "identidades diferentes em diferentes momentos, identidades que não são unificadas ao redor de um 'eu' coerente" (p. 13). Dessa forma, o sujeito caracteriza-se não por uma identidade, mas por diversas identidades. Consideramos, então, que os indivíduos pertinentes ao território não são determinados por uma única identidade. Moradores/as podem ser também torcedores/as, catadores/as, guardadores/as, comerciantes locais. Torcedores/as também podem ser ambulantes, policiais, fiscais, catadores/as.

$\mathrm{Na}$ perspectiva exposta, ao olhar para os sujeitos e grupos permanentes do território, considerando a teia de interdependência ${ }^{9}$ dos estratos funcionais, os caracterizamos como pertencentes a determinado estrato, por suas funções exercidas a priori nas inter-relações estabelecidas, conforme os usos do território. Por exemplo, se um/a morador/a, possui um comércio fixo em sua residência e estiver desempenhando, primordialmente, funções de comerciante no espaço-tempo-vivido pertinente à pesquisa, este sujeito é considerado um/a comerciante local.

\footnotetext{
8 As relações comerciais de artigos do clube se referem especificamente aos/às vendedores/as ambulantes. No entanto, há a loja oficial do Grêmio, situada na parte externa do estádio Arena, fora do escopo do território investigado. $9 \mathrm{Na}$ teia, torcedores/as ocupam posição central nas relações de interdependência, pois a existência de todas essas inter-relações só é possível através da presença de torcedores/as no território.
} 
Quanto aos/às comerciantes locais, estes/as apresentamos em duas categorias: os/as comerciantes fixos/as e os/as comerciantes transitórios/as. Os/ as fixos/as se caracterizam por possuir comércio permantente no território. Já os/ as comerciantes transitórios/as são aqueles/as que transformam suas casas em ambientes comerciais improvisados somente nos dias de jogos, dedicando-se, geralmente, à venda de bebidas e alimentos.

As relações comerciais pintam o território em tonalidades quentes, que borbulham em dias de jogos mais expressivos, como os da Libertadores. O trecho do diário de campo II aponta tal dimensão:

\begin{abstract}
[...] segui rumo à Avenida Leopoldo Brentano passando por entre os/as torcedores/as e ambulantes que tomavam conta das ruas e dos canteiros. Muitas casas abriam as suas portas para se transformar em comercio de bebidas e lanches. Garagens se transformaram em lancherias, canteiros em centros de comércio de churrasquinho, cachorro quente, entrevero, bebidas e artigos que se remetiam ao clube (bonés, camisas, bandeiras, cavalinhos). Embora o número mais expressivo de ambulantes estivesse no canteiro central da avenida, na calçada, à direita (lado que fica localizada a Arena), havia grande número de ambulantes, tanto de venda de bebidas, quanto de artigos do clube. Pontos de ônibus eram lojas a céu aberto. Também passavam por ali catadores/as de latas [...] Ao longo da caminhada, me impressiono com a quantidade de bares, mercearias e lancherias existentes, em que a grande maioria faz alusão ao Grêmio, seja no nome e/ou nas cores do estabelecimento. Do meio para o final da avenida também chamou atenção a quantidade de casas que se transformam em estacionamentos: são calçadas, garagens e pátios que são guardados por mulheres e homens, que ficam no centro da rua chamando por seus/suas clientes, que chegam nos seus veículos, até onde o movimento de torcedores/as ocupando as ruas os/as deixam ir [...] A permanência da grande quantidade de torcedores/as na avenida faz com que todos estabelecimentos tenham concentração de público, embora alguns se destaquem por um maior agrupamento e pelas manifestações exacerbadas de amor ao clube, mediadas por cânticos, tais como o Bar dos Borrachos e o Bar do Ito (02/10/2018).
\end{abstract}

As últimas anotações do diário se remetem justamente à apropriação dos espaços pelo público permanente. Nesse contexto, diferenciamos em duas categorias estes indivíduos, os tratando como sujeitos estáveis e sujeitos circulantes. E para que seja possível caracterizá-los, precisamos primeiramente falar sobre totalidade e fragmentação do território, levando em consideração o pensamento de Santos (2005), sobre os novos recortes do território, atribuindo-lhes conceitos de horizontalidades que são "[...] os domínios da contiguidade, daqueles lugares vizinhos reunidos por uma continuidade territorial" (p. 139) e verticalidades, que "[...] seriam formadas por pontos distantes uns dos outros, ligados por todas as formas e processos sociais" (p.139).

Embora Milton Santos esteja se referindo ao espaço global em proporções maiores de relações macroeconômicas (sociedade brasileira), entendemos que o pensamento também contempla o território investigado. Sobre as verticalidades, consideramos todas as questões de longa distância que tornam o território do dia do jogo uma parte de um tecido da cidade de Porto Alegre, do Brasil, da América Latina, do mundo. E mais especificamente, sobre as horizontalidades, os lugares vizinhos conferem ao território uma totalidade também em si, além de fragmentações interligadas. Desse modo, abordamos os fragmentos territoriais do campo, Ihes 
atribuindo o conceito horizontal de microterritórios em rede, que são singulares em suas especificidades, mas compõem a totalidade vertical de macroterritório Imediações da Arena.

Assim, o macroterritório é considerado a totalidade do campo investigado, composta por fragmentações específicas, que conceituamos microterritórios. Essas partes, mesmo que em rede na composição macro, possuem funcionalidades singulares, nas formas de interação, sujeitos e estratos pertencentes. Observamos, com maior evidência alguns microterritórios, tais como bares, sedes de torcidas, locais fixos de policiamento e de ambulantes. A especificidade na forma de apropriação de um dos microterritórios é contemplada a seguir:

Em frente ao bar dos Borrachos havia muita gente. Boa parte dos torcedores cantavam, ao som dos instrumentos. Ao lado do bar, havia uma escada ocupada por um grupo de torcedores sem camisa que cantavam e levantavam os braços, como se estivessem pendurados no alambrado das arquibancadas (DIÁRIO DE CAMPO IV, 30/10/2018).

Com relação à apropriação dos microterritórios, denominamos sujeitos estáveis, os pertencentes aos estratos funcionais pertinentes ao macroterritório que se apresentam de forma fixa em um microterritório, permanecendo naquele espaço. Já os sujeitos circulantes se caracterizam pela circulação nos diversos microterritórios, sem se fixar em um determinado lugar, remetendo ao um pertencimento mais macro a que microterritorial. Ao pensar as relações estabelecidas entre os sujeitos, através de seus usos dos microterritórios, enxergamos formas de multi-apropriações. Assim, estratos funcionais podem contemplar tanto sujeitos estáveis, quanto circulantes, o que é o caso dos/as torcedores/as e também policiamento, que mesmo se fixando em determinado microterritório, também contemplam sujeitos específicos que circulam entre outros microterritórios.

As apropriações dos microterritórios podem ser visualizadas nas imagens seguintes, pelos sujeitos estáveis ambulantes e nos territórios do Viaduto, lugar do policiamento, que ali são estáveis, mas também exercem apropriação circulante entre os demais espaços. Além de torcedores/as que são estáveis no microterritório do Borrachos, mas não deixam de ser circulantes em outros microterritórios.

Figura 1- Microterritórios de ambulantes- sujeitos estáveis.

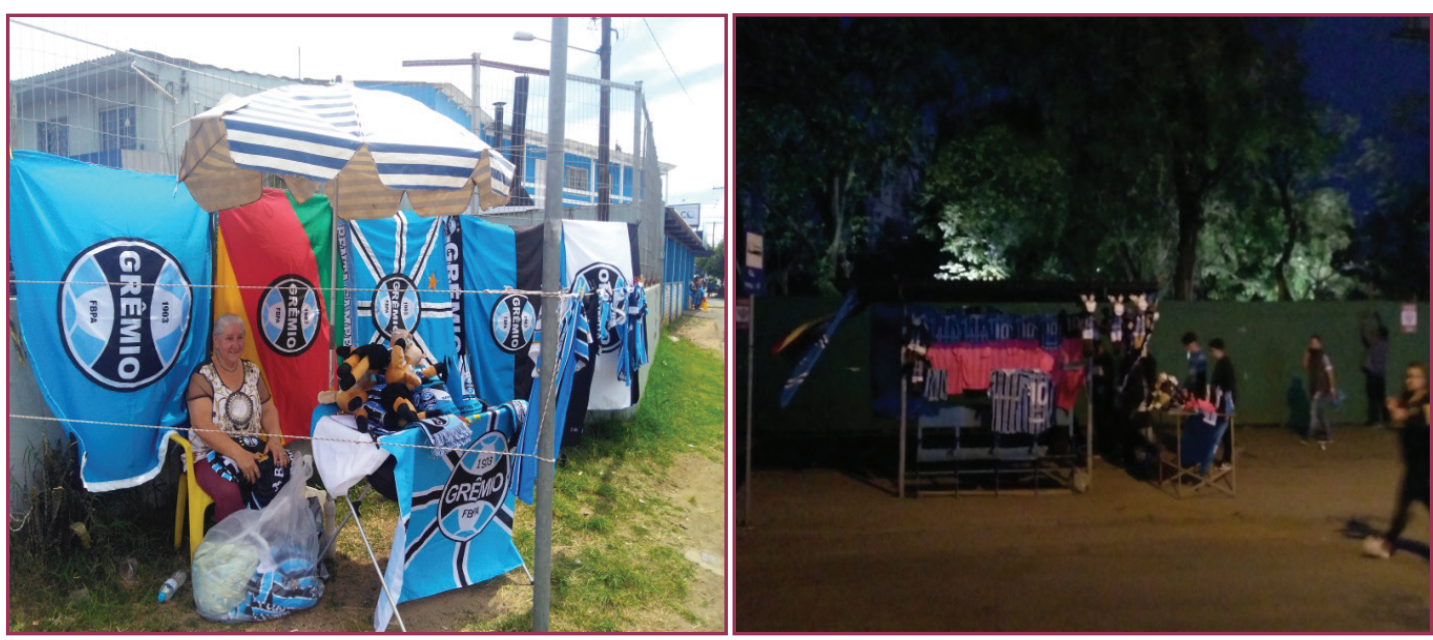

Fonte: imagem fotografada pela pesquisadora, Porto Alegre, 2018. 
Figura 2 - Microterritórios Viaduto e Borrachos - sujeitos estáveis/ circulantes
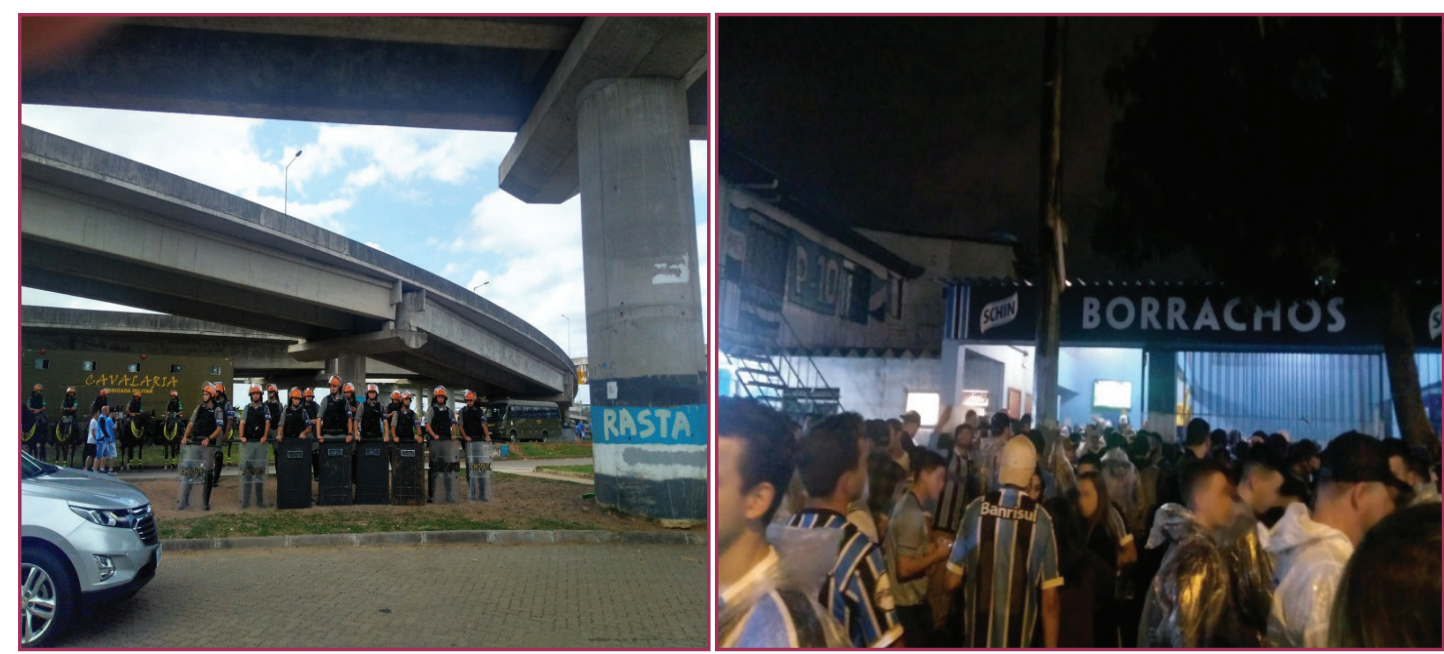

Fonte: imagem fotografada pela pesquisadora, Porto Alegre, 2018.

Além das redes de interdependência dos estratos funcionais, enxergamos outros fatores macro e micro que se inter-relacionam de maneira efetiva nas configurações do território, já que "[...] investigar a totalidade do campo social não significa analisar cada um de seus processos individuais. Implica, acima de tudo, descobrir as estruturas básicas, que dão a todos os processos individuais agindo nesse campo sua direção e marca específica" (ELIAS, 1993, p. 223).

Os fatores micro tratam-se de estruturas básicas do campo que exercem influência na configuração do território, sofrendo variações. Já os fatores macro, são caracterizados pelo aspecto da estabilidade que são imutáveis, pois são pertinentes a todas as formas de configuração do território, independente das variações micro.

\subsubsection{Fatores micro}

Apontamos os fatores micro, os quais configuram o território mutável, pois cada um desses fatores agindo, em suas diversificadas combinações revela que o campo investigado não se trata de um único território fixo, sólido em suas estruturas, mas de um território que apresenta "equilíbrios flutuantes", com arranjos constantes, específicos e provisórios (ELIAS; SCHROTER, 1994). O que acontece a cada jogo depende diretamente das combinações dos seguintes fatores micro: competição; fase na competição; adversário e condições climáticas.

A cada ida a campo, a pesquisadora mergulhava em um território específico nunca idêntico ao anterior e nem ao seguinte. É líquido, pois suas organizações não mantém sua forma por muito tempo, "[...] se decompõem e se dissolvem mais rápido que o tempo que leva para moldá-las e, uma vez reorganizadas, para que se estabeleçam" (BAUMAN, 2007, p. 7). Portanto, dificilmente o território seria compreendido, se partíssemos da única perspectiva de território, enquanto estrutura sólida.

Nesse cenário, os fatores micro determinam a quantidade de público e essa característica quantitativa de torcedores/as no território tem relação direta com seus arranjos e, portanto, com as inter-relações com os demais estratos. Os dias de jogos 
da competição internacional concentravam maior quantidade de público e a fase mais avançada nesta competição, comportava uma saturação ainda maior. A inter-relação entre quantidade de público, competição e fase na competição pode ser constatada no diário de campo IV, na fase de semifinal da Libertadores:

[...] caminhei toda avenida, em meio à multidão sem conseguir visualizar quase nada a não ser muita, muita gente junta. Parecia que aquela avenida não tinha fim. Era tudo parecido com o dia do jogo contra o Tucuman, ao mesmo tempo que era muito diferente, já que tudo estava lá: ambulantes, comerciantes, cambistas, catadores/as, o policiamento, os/as moradores/ as, os/as torcedores/as e eu. No entanto, era como se tivessem colocado fermento no território [...] A sensação que tive, ao atravessar a avenida era de que o território estava trasbordando [...] a circulação pela avenida já estava bastante dificultosa. Era muita gente parada nas calçadas e no meio da rua (DIÁRIO DE CAMPO IV, 30/10/2018).

Com relação às temperaturas do território que aparecem nos diários de campo, essas demonstram as configurações flutuantes existentes. Se no dia de jogo contra o River Plate, o território transbordava, contra o Tucuman ele borbulhava "pelo cenário frenético de efervescência desordenada, ou desordem efervescente daquele território" (DIÁRIO DE CAMPO II, 2/10/2018). Já no dia de jogo contra a Chapecoense, no campeonato brasileiro, a temperatura estava bem mais amena:

[...] se eu fosse definir o campo em uma temperatura, esta seria morna: sem efervescência do lado de fora e jogo tranquilo do lado de dentro. Até a saída do estádio era de vagar. Isso foi evidenciado por uma ambulante, que ao passar por ela, em minha direção ao ônibus, escuto-a exclamar "que gente morta! Nem parece que ganharam!" (DIÁRIO DE CAMPO VI, 18/11/2018).

Os adversários de clubes mais expressivos, por exemplo, os times com maior status no cenário nacional, que contemplam principalmente os estados de São Paulo, Rio de Janeiro e Minas Gerais, somados à fase do campeonato também são dois fatores determinantes. $\mathrm{O}$ jogo contra o Corinthians, que era o último jogo do Grêmio no campeonato brasileiro e que a vitória garantia vaga direta na Libertadores 2019 , foi o dia de maior quantidade de torcedores/as nas imediações da Arena, pertinente a esta competição.

As condições climáticas também exercem influencias configuracionais no território, já que em dias chuvosos, tanto torcedores/as quanto ambulantes se reorganizam espacialmente, abandonando lugares que costumam se fixar, a céu aberto, para ocupar espaços abrigados, como, por exemplo, a parte de baixo da rampa da Arena (figura 3, na próxima página). Em um dia de chuva, foi observado que "o espaço da rampa foi onde mais havia quantidade de torcedores/as parados/as e consumindo alimentos, já que nos demais setores os/as torcedores/as estavam em deslocamento para entrar no estádio. Muitos/as deles/as protegidos/as pelas capas e por guarda-chuva" (DIÁRIO DE CAMPO I, 23/09/2018).

Esse microterritório, em dias não chuvosos comporta menor número de torcedores/as e de ambulantes, pois os/as demais ocupam as calçadas e canteiro da Padre Brentano, uma parte da AJ Renner e o entorno da Arena. Assim, consideramos o território flutuante, com arranjos múltiplos a cada dia de jogo, de acordo com os fatores micro que possuem influência direta no espaço-tempo-vivido. 
Figura 3 - Microterritório Rampa, em dia chuvoso.

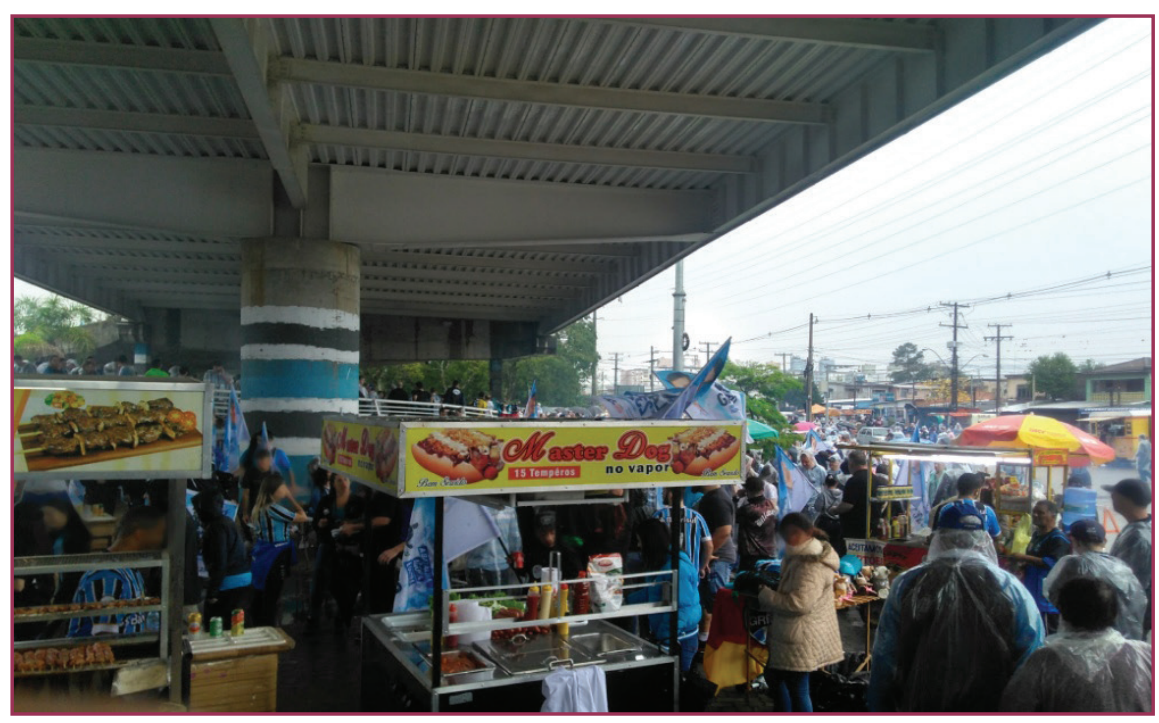

Fonte: imagem fotografada pela pesquisadora, Porto Alegre, 2018.

\subsubsection{Fatores macro}

Mesmo que sejam evidentes os fatores que caracterizam o território mutável, destacamos que não é porque o campo apresenta estruturas líquidas que também não possui suas bases sólidas. E ao olhar especificamente para estas bases, enxergamos também um território estável, configurado pelos fatores macro. Estes fatores são a sociabilidade e as relações comerciais. Essas características constantes do território foram pertinentes a todas as idas a campo, mesmo com a interferência das combinações dos fatores micro.

As relações comerciais no território possuem sua centralidade nos/as torcedores/as, pois são os/as principais consumidores/as de alimentos, bebidas e artigos relacionados ao clube (camisas, bonés, chapéus, bandeiras, entre outros). Os/as gremistas consomem nos estabelecimentos locais, nos/nas ambulantes e o consumo de bebidas ocasiona geração de renda aos/às catadores/as de latas.

Os/as guardadores/as de veículos também fazem parte dessa rede, ao lucrarem com a função exercida para os/as torcedores/as, que se locomovem com seus veículos de passeio até o estádio ou com os ônibus de excursões vindas, principalmente, do interior do estado. É necessário apontar que o período de pesquisa ocorre em uma época de "boa fase" para o Grêmio, que era o atual campeão de Libertadores da América, além de estar obtendo títulos e resultados positivos também em outras competições que disputou, desde a inauguração da Arena.

Quanto às relações de sociabilidade, são fatores estáveis do território e também se relacionam com o fator relações comerciais, já que as imediações da Arena é ponto de encontro entre gremistas e esses encontros acontecem nos bares, nos lares, nos canteiros, nas calçadas, no meio da rua. Quem não traz sua bebida de casa, compra por ali. Cambistas e guardadores/as estão ativos para atender que chega cedo e os/as catadores/as estão em circulação permanentemente, pois o tempo todo há consumo. A cerveja e o churrasco possuem valor simbólico na confraternização. 
Os/as ambulantes também chegam cedo e os/as comerciantes locais abrem suas portas, recepcionando os/as torcedores/as que circulam horas antes, durante e horas depois do jogo. Se para os/as comerciantes, ambulantes, catadores/as, guardadores/as e cambistas o território é um lugar de trabalho, para os/as torcedores/ as é um cenário de festividade, de celebração do dia de jogo, em que eles/as são os/ as protagonistas do acontecimento.

A festa é mediadora entre os anseios individuais e coletivos. Não se trata de "somente significar o objeto, mas celebrá-lo [...] em utilizar meios de expressão para fazer aparecer o valor que se atribui a esse objeto" (AMARAL, 1998, p. 39). Portanto, para os/as gremistas, chegar cedo, viajar por horas, percorrer centenas de quilômetros de estrada, sair mais cedo do trabalho, não ir ao trabalho, fazer o churrasco no canteiro, na calçada, nos bares, carregar instrumentos, levantar uma mão enquanto entoa os cânticos da torcida e na outra mão segurar o copo de cerveja, são expressões do significado que tem o dia de jogo.

Amaral (1998) atenta que "toda festa é um ato coletivo, ela supõe não só a presença de um grupo, mas também sua participação" (p. 39 e 40). Assim, para torcedores/as festejar o dia de jogo é vestir com orgulho a camisa tricolor, é ser tricolor e estar entre tricolores. É reforçar, nos microterritórios os laços de pertencimento. É fazer parte da festa gremista, do ambiente esportivo, do lugar da permissão e estímulo das manifestações emotivas, dos gestos exagerados, da embriaguez coletiva. É também a oportunidade de estabelecer alianças com outras torcidas, como pudemos verificar em um dia de jogo contra o Vasco da Gama, time do estado do Rio de Janeiro:

Fui literalmente os seguindo [torcedores do Vasco] até o Bar D' Julia, onde já havia um grupo de torcedores gremistas fazendo seu tradicional churrasco. Os torcedores do Vasco, foram até ali e cumprimentaram os torcedores da casa, trocaram algumas palavras e seguiram pela Padre Brentano. Um dos churrasqueiros comenta com outro que "tem que receber bem porque a gente sempre é bem recebido quando chega lá" (...) Segui rumo à Avenida, na mesma direção que se dirigiram os torcedores do Vasco e deparei com um grupo ainda maior junto aos torcedores gremistas no Buteco 1903. Aproveitei a oportunidade para abordar dois deles para uma conversa (...) Eles contam que esse tipo de aliança acontece também com torcidas de outros clubes, de outros estados e que a disputa se restringe somente ao interior do estádio, na hora do jogo. Depois que a partida termina, independente do resultado, a confraternização segue do lado de fora do estádio (DIÁRIO DE CAMPO V,11/11/2018).

O território das imediações da Arena é também a festa no espaço público. Quase tudo é público, com exceção de alguns espaços alugados para grupos específicos de torcedores/as, moradores/as que fazem suas festividades privadas e aqueles/as que mantém as portas de suas casas fechadas, sem interagir com o que acontece do lado de fora.

Bauman (2008) afirma que na sociedade de consumidores, "se adaptar aos preceitos da cultura de consumo e segui-los estritamente é, para todos os fins e propósitos práticos, a única escolha aprovada de maneira incondicional" (p. 71). Ao dialogarmos com GASTALDO (2005), sobre o "consumo coletivo dos jogos de futebol" (p.119), o que visualizamos nas imediações da Arena é que a celebração estabelece 
inter-relações entre consumo e sociabilidade que transcendem o próprio jogo. O campo investigado é o território de quem é/está do lado de fora do estádio e, justamente por ser o lado de fora, que se estabelecem essas inter-relações sólidas entre os fatores macro de sociabilidade e relações comerciais. E o lado de fora é o lado de dentro do círculo de celebração, dos/as que festejam o dia de jogo e de quem dá suporte à festa.

\section{CONSIDERAÇÕES}

Nas imediações da Arena do Grêmio, situada na zona periférica norte da cidade de Porto Alegre/RS, a apropriação do território, no período que antecede a realização do jogo, se configura na interdependência. Torcedores/as, moradores/as, comerciantes, vendedores/as ambulantes, policiamento, fiscalizadores/as, cambistas, guardadores/as de veículos e eleitoreiros/as configuram estratos funcionais do campo que se inter-relacionam. O território é constituído pela interação, a partir da existência de torcedores/as em dias de jogos. Moradores/as comercializam alimento, bebida, espaço físico da residência aos/às torcedores/as. Catadores/as, por sua vez, recolhem as latas de bebidas, para também comercializá-las. O policiamento e fiscalizadores/as dão conta da segurança. E, nessa teia de inter-relações, os demais estratos também estabelecem suas funções.

Trata-se de um único território: o entorno do estádio, em dias de jogos, contemplando o espaço compartilhado por diferentes sujeitos, com diversificadas funções, que atribuem significações específicas ao espaço-tempo-vivido de um bar, uma sede, um canteiro, uma esquina, uma garagem. Espaços públicos e privados se constituem como lugares específicos de apropriação e dominação do espaço. Esses microterritórios, funcionalizados em rede, dão forma à totalidade territorial das imediações da Arena do Grêmio. Desse modo, o que visualizamos é um território dicotômico, que é unitário, na sua totalidade e plural, nas suas fragmentações.

O território é mutável nos fatores micro: condições climáticas, competição, fase na competição, adversário. Conforme se dão a combinações desses fatores, o cenário se recompõe. Nos dias de chuva, há o esvaziamento dos espaços a céu aberto e maior lotação dos espaços abrigados. No entanto, nas noites de libertadores, a chuva não é barreira. Toda extensão da avenida permanece ocupada e a forma de se proteger são as capas de chuva. Também é estável, nos fatores macro: sociabilidade e relações comerciais. Para os/as torcedores/as, é o dia do encontro, da confraternização entre os pares e torcidas aliadas. Para outros sujeitos, é oportunidade de fonte de renda. Assim, independente dos fatores micro, os macro constituem aspectos constantes e também inter-relacionados, a cada dia de jogo.

Comercializa-se bebidas, refeições, artigos com as cores e o símbolo do Grêmio, capas de chuva, ingressos, garagens, calçadas, pátios, salões, a rua. As latas são recolhidas para também serem comercializadas e os/as eleitoreiros/as vendem a imagem de seus candidatos, que são referências clubística para os/as gremistas. É, portanto, cenário de festividade dos/as torcedores/as e de trabalho, para os demais estratos. Celebrar e trabalhar são formas inter-relacionadas de fazer a festa do pertencimento clubístico acontecer. 
As imediações da Arena se constituem na indissociabilidade espaço-tempo vivido, onde torcedores/as ocupam posição central na teia configuracional, o que os atribui funcionalidade de estrato protagonista. O território é configurado nas ambiguidades, na multiplicidade de inter-relações, significados e pertencimentos, inerentes à apropriação e dominação do espaço, que contemplam toda vida social que pulsa do lado de fora do estádio de futebol, mas do lado de dentro da celebração do dia de jogo.

\section{REFERÊNCIAS}

AMARAL, Rita de Cássia de Mello Peixoto. Festa à Brasileira: Significados do festejar, no país que "não é sério". 1998. 387 f. Tese (Doutorado em Antropologia social) - Faculdade de Filosofia, Letras e Ciências Humanas, Universidade de São Paulo, São Paulo, 1998.

ANGROSINO, Michael. Etnografia e observação participante. Porto Alegre: Artmed, 2009.

BAUMAN, Zygmunt. Tempos líquidos. Rio de Janeiro: Jorge Zahar, 2007.

BAUMAN, Zygmunt. Vida para consumo: a transformação das pessoas em mercadorias. Rio de Janeiro: Jorge Zahar, 2008.

BIANCHI, Greison. Agentes e práticas da organização capitalista do espaço: o espetáculo do bairro Humaitá. 2012. 75f. Monografia (Bacharel em Ciências Sociais) Instituto de Filosofia e Ciências Humanas, Universidade Federal do Rio Grande do Sul, Porto Alegre, 2012.

DAMO, Arlei Sander. Futebol e identidade social: uma leitura antropológica das rivalidades entre torcedores e clubes. Porto Alegre, Ed. Universidade/ UFRGS, 2002.

DAMO, Arlei Sander. Do dom à profissão: a formação de futebolistas no Brasil e na França. São Paulo: Aderaldo \& Rothschild; ANPOCS, 2007.

ELIAS, Norbert. O processo civilizador: uma história dos costumes. Rio de Janeiro: Jorge Zahar, 1994. v. 1.

ELIAS, Norbert. O processo civilizador. Rio de Janeiro: Jorge Zahar, 1993. v. 2.

ELIAS, Norbert; SCHROTER, Michael (org.). A sociedade dos indivíduos. Rio de Janeiro: Jorge Zahar, 1994.

GASTALDO, Édison. O complô da torcida: futebol e performance masculina em Bares.

Horizontes antropológicos, v. 11, n. 24, p. 107-123, jul./dez. 2005.

GOMES. Edlaine de Campos; MENEZES, Rachel Aisengart. Etnografias possíveis: "estar" ou "ser" de dentro. Ponto Urbe Revista do núcleo de antropologia urbana da USP, n.3, 2008. DOI: https://doi.org/10.4000/pontourbe.1748.

HAESBAERT, Rogério. O mito da desterritorialização: do "fim dos territórios" à multiterritorialidade. 5. ed. Rio de Janeiro: Bertrand Brasil, 2010.

HAESBAERT, Rogério. Território e multiterritorialidade: um debate. Geographia, v,9, n. 17, 2007. DOI: https://doi.org/10.22409/GEOgraphia2007.v9i17.a13531. 
HALL, Stuart. A identidade cultural na pós-modernidade. 10. ed. Rio de Janeiro: DP\&A, 2005.

MARTINS, Daniella Paula. O Humaitá de ontem, de hoje e de amanhã. 2010. $126 \mathrm{f}$.

Dissertação (Mestrado em Geografia) - Instituto de Geociências, Universidade Federal do Rio Grande do Sul. Porto Alegre, 2010.

MARTINS, Heloísa Helena de Souza. Metodologia qualitativa de pesquisa. Revista Educação e pesquisa, v. 30, n. 2, p. 289-300, maio/ago. 2004.

OLIVEIRA, Roberto Cardoso de. O trabalho do antropólogo. 2. ed. Brasília: Paralelo 15; São Paulo: Editora Unesp, 2006.

RAFFESTIN, Claude. Por uma geografia do poder. São Paulo: Ática, 1993.

SANTOS, Milton. Da totalidade ao lugar. São Paulo: Ed. da Universidade de São Paulo, 2005.

SILVA, Helio R. S. A situação etnográfica: andar e ver. Horizontes Antropológicos, v. 15, n. 32, p. 171-188, jul./dez. 2009.

\section{Apoio:}

O presente trabalho foi realizado com apoio da Coordenação de Aperfeiçoamento de Pessoal de Nível Superior -Brasil (CAPES) - Código de Financiamento 001. This study was financed in part by the Coordenação de Aperfeiçoamento de Pessoal de Nível Superior - Brasil (CAPES) - Finance Code 001. 